\title{
Dietary modulation of ghrelin and leptin and gorging behavior after weight loss in the obese Zucker rat
}

\author{
B Beck ${ }^{1,2}$ and S Richy ${ }^{2}$ \\ ${ }^{1}$ INSERM, U954, Nutrition, Génétique et Exposition aux Risques Environnementaux, Faculté de Médecine, BP 184, F-54505 Vandoeuvre Cedex, France \\ ${ }^{2}$ Université Henri Poincaré, EA 3453, F-54000 Nancy, France \\ (Correspondence should be addressed to B Beck; Email: bernard.beck@nancy.inserm.fr)
}

\begin{abstract}
In this study, we measured ghrelin and leptin in obese Zucker rats after weight loss induced by calorie restriction using either a low-fat (LF) or high-energy palatable (HEPa) diet. After weight loss, the animals were refed lab chow and offered one hour-palatable test meals on the second and fifteenth days of refeeding. Both LF and HEPa rats lost $10 \%$ of their initial body weight $(P<0 \cdot 0001)$. Plasma ghrelin increased with calorie restriction in both groups $(P<0 \cdot 002)$ with a tendency to a higher increase in the HEPa group while plasma leptin decreased only in the LF group $(P<0 \cdot 01)$. Both groups ate the same quantity of chow
\end{abstract}

during refeeding and both groups gorged on palatable diet during test meals at a very high constant intensity in HEPa rats. After one week of refeeding, ghrelin levels remained elevated in HEPa rats $(+33 \cdot 2 \% ; P<0 \cdot 001)$ while returning to baseline in LF rats. Plasma leptin remained low in LF rats. We conclude that weight loss on a palatable diet is possible if total energy intake is controlled. After stopping restriction, when a palatable diet is available, observed gorging might be dependent on specific ghrelin and leptin changes.

Journal of Endocrinology (2009) 202, 29-34

\section{Introduction}

Ghrelin is a powerful stimulator of food intake and has been detected in both the brain and the periphery (vanderLely et al. 2004). Ghrelin release into the blood is dependent on the nutritional state and diet composition (Tschop et al. 2000, Cummings et al. 2001, Beck et al. 2002, 2003, Gomez et al. 2004, Moesgaard et al. 2004, Sanchez et al. 2004). In association with proteins, fats play an important role in regulating ghrelin secretion (Lee et al. 2002, Beck \& Richy 2008, Qi et al. 2008).

Various types of dietary manipulations have been proposed for inducing weight loss (LaraCastro \& Garvey 2004, Dansinger et al. 2005). These dietary alterations are often associated with calorie restriction. Thus, these methods are often successful and induce variable but significant weight loss. However, the most important problem is the long-term maintenance of weight loss after the cessation of weight loss program. The reasons for weight rebound are not fully understood as calorie restriction modifies many regulatory systems, including that of ghrelin. Baseline levels, meal peaks, and nocturnal rises in ghrelin levels are increased by chronic calorie restriction in both normal humans and rats (Barazzoni et al. 2003, Leidy et al. 2007), likely in order to restore energy balance. However, increased (Cummings et al. 2002, Hansen et al. 2002) or unchanged (Morpurgo et al. 2003, Reinehr et al. 2005) ghrelin levels have been reported in obese subjects after restriction.

The Zucker fa/fa rat is a widely used animal model of obesity with hyperinsulinemia and hypertriglyceridemia (Bray 1977). It is also characterized by the downregulation of ghrelin in order to limit adiposity development (Beck et al. 2004) as in obese subjects and rodents (Tschop et al. 2001, Williams et al. 2006). Moreover, its ghrelin system remains operational and responds to food deprivation (Beck et al. 2003). To ascertain the role of ghrelin in weight regulation in obesity and its link with diet type, we studied the effects of calorie restriction and refeeding on body weight and changes in circulating ghrelin in obese Zucker rats. Energy restrictions were imposed by providing limited and fixed isoenergetic quantities of either a low-fat (LF) diet or a highly palatable (high-fat/sweet) diet. We also investigated leptin variations in our experiment because ghrelin and leptin are closely and reciprocally regulated (Barazzoni et al. 2003, Kalra et al. 2003) and despite the mutation in the leptin receptor gene (Chua et al. 1996, Iida et al. 1996), the obese Zucker rat is not totally leptin unresponsive. It shows a blunted response after leptin injection (AlBarazanji 
et al. 1997, Wang et al. 1998) presenting therefore a leptin resistance that is also present in obese subjects (Considine et al. 1996).

\section{Materials and Methods}

The study was conducted in accordance with the NIH Guide for the Care and Use of Laboratory Animals.

\section{Animals and protocol}

For this experiment, we used 48 male six-month-old obese Zucker $(\mathrm{fa} / \mathrm{fa}$ ) rats bred in our laboratory. The rats were placed in individual wire cages in an air-conditioned vivarium with a $12 \mathrm{~h}$ light: $12 \mathrm{~h}$ darkness cycle (lights on at $0900 \mathrm{~h}$ ). They were given access to standard lab chow (A04, SAFE, Villemoisson sur Orge, France) and tap water ad libitum.

After 2 weeks of habituation to these conditions, 12 rats were killed by decapitation (T0) $3 \mathrm{~h}$ after the beginning of the light period. Food was withdrawn during this 3 -h period in order to ensure that all animals were in the same nutritional state. This time was also chosen in order to minimize interference with circadian hormonal rhythms as both ghrelin and leptin present a nocturnal rise (Sinha et al. 1996, Cummings et al. 2002). These conditions were used for all blood samplings.

The remaining rats were randomly divided into two body weight-matched groups that were food-restricted for 3 weeks. The animals were provided $48 \mathrm{kcal} /$ day of either a LF diet (12 g/day; $n=18$ ) or a high-energy palatable diet (HEPa; $9.8 \mathrm{~g} /$ day; $n=18$ ). Food was given in food cups during the first hour of the light period. The LF diet contained $20 \%$ protein, $64 \%$ carbohydrates, and 16\% fats (\% of total energy), whereas the HEPa diet contained $18 \%$ protein, 32\% carbohydrates, and 50\% fats (cf. Table 1). We have previously shown that the HEPa diet is particularly appetizing to normal rats (Beck et al. 2005).

After 3 weeks of energy restriction, 12 randomly chosen rats (six per group) were killed by decapitation (T21). All remaining rats had access to A04 chow ad libitum for 3 weeks. The A04 chow diet contained 5\% of energy as fats and had an energy density of $2.9 \mathrm{kcal} / \mathrm{g}$. At the end of the first day of refeeding on chow (T22), all rats were offered a test meal consisting of HEPa diet available ad libitum for $1 \mathrm{~h}$. This procedure was repeated 2 weeks later (T35). The rats were killed by decapitation at the end of the 3-week period of A04 chow refeeding (T42) ad libitum.

\section{Samplings and measurements}

Blood samples were taken from the tail vein at the beginning (T0) and end of the calorie restriction period (T21) and 1 week after refeeding on A04 chow (T28). All samples $(0 \cdot 8 \mathrm{ml} / \mathrm{rat})$ were collected in aprotinin-EDTA chilled plastic

Table 1 Composition of the high-energy palatable (HEPa) and lowfat (LF) diets

\begin{tabular}{l} 
Quantity $(\mathrm{g} / \mathrm{kg})$ \\
\hline $\mathrm{HEPa}$ \\
\hline
\end{tabular}

Ingredient
Starch
Sucrose
Margarine and oil (50/50
Casein
Sweet condensed milk
Salts
Vitamins $^{\text {b }}$
Cellulose
Caloric density (kcal/g)
Energy (\%) supplied by
Carbohydrates (C)
Fat (F)
Protein

${ }^{a}$ Mixture 205 b.

${ }^{b}$ Mixture 200 (UAR - Villemoisson sur Orge-France). Each diet was supplemented with $0 \cdot 2 \%$ methionine.

tubes, and centrifuged at $4{ }^{\circ} \mathrm{C}$ for $20 \mathrm{~min}$; plasma was aliquoted for subsequent assays.

When the rats were killed at T0, T21, and T42, different fat pads (perirenal, epididymal, and abdominal s.c. adipose tissue) were sampled and weighed to estimate adiposity.

Chow intake was measured every other day from T21 to T42 except on the first day of chow refeeding when it was measured after 1,6 , and $24 \mathrm{~h}$ of refeeding and during the $24 \mathrm{~h}$ that followed each test meal. Intake of HEPa diet during the 1-h test meal was also measured.

\section{Assays}

All samples were measured in the same assay for each hormone.

Total ghrelin was measured in duplicate in diluted plasma from the tail vein and trunk blood samples by a specific RIA kit (RK-031-31, Phoenix Europe GmbH, Karlsruhe, Germany) as previously described (Beck et al. 2003). For this experiment, maximal binding was $47 \cdot 2 \%$, non-specific binding was $2 \cdot 0 \%$, and IC50 was $31 \cdot 9 \mathrm{pg} /$ tube.

Leptin was measured in duplicate in diluted plasma of the same samples by a specific RIA kit (RL-83K, Linco, St Charles, MO, USA). For this experiment, maximal binding was $54 \cdot 2 \%$, non-specific binding was $2 \cdot 3 \%$, and IC50 was $2 \cdot 9 \mathrm{ng} / \mathrm{ml}$.

\section{Statistical analysis}

Results are reported as means \pm s.E.M. Means were compared by two-way variance analysis (diet type $X$ feeding condition) and variance analysis for repeated measures followed by PLSD Fisher's test when necessary using the Statview software (SAS Institute Inc, Cary, NC, USA). A probability of $<0 \cdot 05$ was considered statistically significant. 


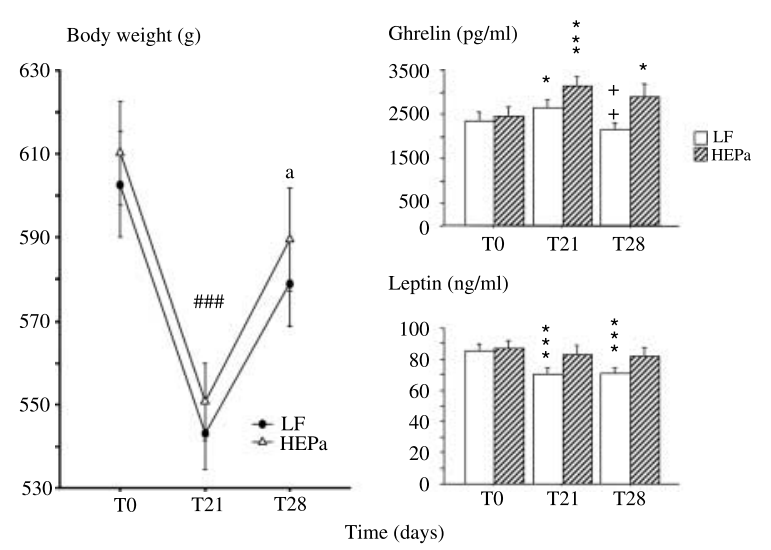

Figure 1 Body weight and plasma ghrelin and leptin variations induced by the low-fat (LF) and high-energy palatable (HEPa) diets given in restricted but isocaloric quantities in obese Zucker rats for 3 weeks and after 1 week of refeeding. ${ }^{\# \#} P<0 \cdot 001$ versus initial BW for both groups; ${ }^{*} P<0 \cdot 02$ versus same group at T0; ${ }^{* *} P<0 \cdot 01$ versus same group at $\mathrm{T} 0 ;{ }^{++} P>0.01$ versus same group at $\mathrm{T} 21$; ${ }^{\mathrm{a}} P>0.03$ versus $\mathrm{T} 21$ for both groups.

\section{Results}

Effects of energy restriction on body weight, adiposity, and hormone levels

Body weight and adiposity Initial body weights of the LF and HEPa rats were similar. There was a significant effect of energy restriction $(P<0 \cdot 0001)$ but not of diet type on body weight. Both groups lost about $10 \%$ of their initial body weight during the 3 weeks of restriction (Fig. 1 left). At the end of this period, there was no significant difference in body weight between LF and HEPa rats. Changes in adipose tissue weights are shown in Table 2. There was a significant effect of energy restriction on the weight of each fat depot (epididymal, $P<0 \cdot 001$; perirenal, $P<0 \cdot 02$; and s.c. abdominal, $P<0 \cdot 01)$.

Plasma hormones There was a significant effect of energy restriction $(P<0 \cdot 01)$ and a strong trend for diet type
$(P=0 \cdot 06)$ on plasma ghrelin levels. After weight loss, plasma ghrelin concentration rose by $19 \%$ in LF rats $(P<0 \cdot 02)$ and by $30 \%$ in HEPa rats $(P<0 \cdot 001$; Fig. 1 top right $)$. The difference between the two groups did not reach statistical significance.

Energy restriction led to a significant decrease in leptin levels in LF rats $(-17 \% ; P<0 \cdot 01$; Fig. 1 bottom right), but not in HEPa rats. At the end of the restriction period, leptin concentration in HEPa rats tended to be higher than in LF rats $(P=0 \cdot 07)$.

Effects of refeeding ad libitum on feeding behavior, body weight, and hormone levels

Feeding and body weight Chow intake measured after 1 , 6 , and $24 \mathrm{~h}$ of feeding ad libitum is shown in Fig. 2 (left). There was no difference in food intake between the groups at any time. All of the rats ate a large meal (6-7 $\mathrm{g}$ of chow) during the first hour of refeeding.

Intakes of the HEPa diet during the two $1 \mathrm{~h}$ test meals on days 22 and 35 are shown in Fig. 2 (right). There was a significant effect of group $(P<0 \cdot 0001)$. On day 22, HEPa rats consumed more than twice as much food as LF rats $(P<0 \cdot 0001)$. During test meal two after 2 weeks of refeeding, both groups ate a very large meal but the difference in intake between HEPa and LF rats was no longer significant. Total energy intake during the second day of refeeding (test meal + chow) was significantly greater in $\mathrm{HEPa}$ than in LF rats $(103.4 \pm 3.5$ vs $84.8 \pm 2.8 \mathrm{kcal}$; $P<0 \cdot 001)$. However, there was no significant difference in total energy intake during the entire first week of refeeding $(539 \cdot 2 \pm 14 \cdot 4 \mathrm{kcal}(\mathrm{LF})$ vs $548 \cdot 1 \pm 19 \cdot 3 \mathrm{kcal}(\mathrm{HEPa}))$ or during the entire refeeding period $(1470 \cdot 4 \pm 42 \cdot 2 \mathrm{kcal}(\mathrm{LF})$ vs $1466 \cdot 1 \pm 46 \cdot 7 \mathrm{kcal}(\mathrm{HEPa}))$.

After 3 weeks of refeeding, all rats had returned to their initial body weight and were even slightly heavier. Refed $\mathrm{HEPa}$ rats weighed significantly more at the end of the experiment than at the beginning $(622 \cdot 1 \pm 13 \cdot 7$ vs $610 \cdot 2 \pm 12 \cdot 3 \mathrm{~g} ; P=0 \cdot 02)$; however, the difference between final and initial body weight was not significant for LF rats

Table 2 Changes in adipose tissue depots and body weights (mean \pm s.E.M. in g) after energy restriction and refeeding in high-energy palatable (HEPa) and low-fat (LF) diet-restricted obese Zucker rats

Epididymal AT

\section{Depot}

Initial T0

End of energy restriction T21

LF rats

HEPa rats

End of refeeding T42

LF rats

$14 \cdot 4 \pm 0 \cdot 8$
$10 \cdot 0 \pm 1 \cdot 1^{*, l l}$
$11 \cdot 9 \pm 1 \cdot 2^{\ddagger}$
$14 \cdot 1 \pm 0 \cdot 4$
$15 \cdot 0 \pm 0 \cdot 7$

HEPa rats
Perirenal AT

$16 \cdot 7 \pm 1 \cdot 8$

$12 \cdot 4 \pm 1 \cdot 0^{\ddagger}$

$12 \cdot 7 \pm 1 \cdot 6^{\ddagger}$

$16 \cdot 9 \pm 1 \cdot 2$

$18 \cdot 6 \pm 1 \cdot 5$
S.c. abdominal AT

BW

AT, adipose tissue; s.c., subcutaneous. ${ }^{*} P<0 \cdot 001$ versus same group refed; ${ }^{\dagger} P<0 \cdot 01$ versus same group refed; ${ }^{\ddagger} P<0 \cdot 03$ versus same group refed; ${ }^{\S} P<0 \cdot 001$ versus initial; " $P<0.01$ versus initial; " $P<0.03$ versus initial.

${ }^{a}$ Mean for all rats. 


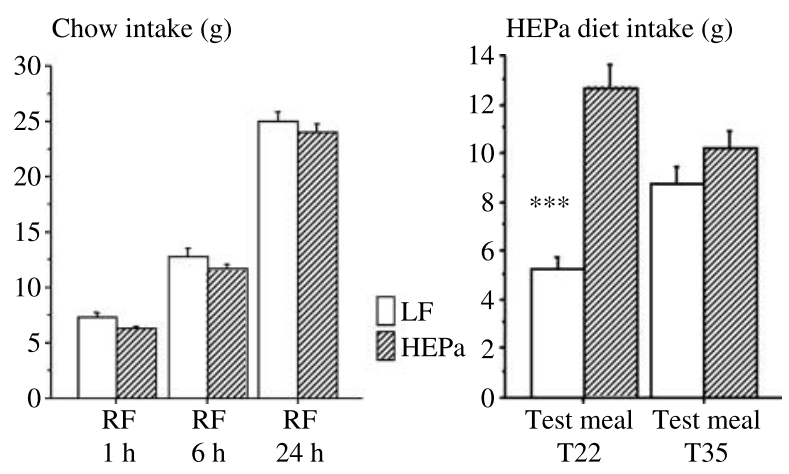

Figure 2 Food intake during the first hour, 6 first hours, and first day of refeeding on chow diet (left), and during the two test meals given during refeeding (right) in the low-fat (LF) and high-energy palatable (HEPa)-restricted obese Zucker rats ( $n=12$ per group). ${ }^{* * *} P<0 \cdot 001$ versus HEPa rats.

$(611 \cdot 1 \pm 12 \cdot 0 \mathrm{~g}$ (final) vs $602 \cdot 8 \pm 12 \cdot 6 \mathrm{~g} ; P=0 \cdot 10)$. The rats regained $63 \%$ and about $25 \%$ of their weight during the first and second weeks respectively. In both groups, the final weights of the three fat depots were no longer significantly different from the initial weights (Table 2).

Plasma hormones After 1 week of refeeding (Fig. 1), plasma ghrelin levels decreased significantly in LF rats $(P<0 \cdot 01)$ and were no longer different from the initial levels. In HEPa rats, plasma ghrelin levels had not changed since the end of calorie restriction and remained significantly higher than the initial level $(P<0 \cdot 02)$. Plasma leptin levels did not vary and remained significantly lower than the initial levels in LF rats only $(P<0 \cdot 001)$.

At the end of the refeeding period, there was no difference in ghrelin and leptin levels between LF and HEPa rats.

\section{Discussion}

While behavioral approaches to managing obesity have been successful in achieving clinically significant weight loss, the long-term maintenance of weight loss remains a problem. Mechanisms for weight regain, particularly those involving hedonic processes are not fully understood. In this study, we had two objectives. First, we wanted to evaluate whether diet palatability influenced weight loss and regain; secondly, we wanted to evaluate whether the hormone changes induced by energy restriction and refeeding could explain the weight changes. We used 6-month-old obese Zucker rats that had developed a marked adiposity and focused on ghrelin and leptin, two hormone systems with opposing effects on BW regulation. Ghrelin stimulates food intake and BW gain, whereas leptin inhibits feeding and induces weight loss (Kalra et al. 2003). Dietary BW manipulations were done by providing restricted and fixed isoenergetic quantities of either a LF or HEPa diet. Both diets contained the same ingredients except for sweet condensed milk, which contributed with margarine and oil to the enhanced palatability of the high-energy diet.

We showed that similar weight loss and adiposity changes could be achieved with intake of a restricted amount of a palatable diet as with intake of a LF diet. These results underscore the fundamental importance of calorie restriction as opposed to macronutrient composition for weight loss. These results agree with studies in humans (Golay et al. 1996). Thus, it is possible for obese people to lose weight by consuming limited amounts of pleasant food instead of less palatable meals. Incorporating this information into dietary regimens could facilitate greater weight loss by promoting better adherence to weight loss programs. It has been shown that adherence to a low carbohydrate diet is better than adherence to LF diet (Yancy et al. 2004).

Although differences in diet composition did not affect gross body parameters (BW and adiposity), diet composition appeared to have a more subtle influence on the hormone systems that participate in BW regulation. Plasma ghrelin and leptin concentrations were modified differently by a food restriction induced with a LF diet or a HEPa diet. At the end of the restriction period, plasma ghrelin was increased in both groups of rats with a trend towards a greater increase in HEPa rats. This confirms that the ghrelin system is upregulated by a sufficient level of weight loss. According to previous reports (Cummings et al. 2002, Hansen et al. 2002, Morpurgo et al. 2003, Reinehr et al. 2005) and our results, this threshold is around $10 \%$ of the initial BW. Plasma leptin levels were unaffected by 3 weeks of a calorie-restricted high-fat diet, whereas plasma leptin decreased in rats fed a LF diet for 3 weeks. These data suggest that the dietary fat content plays a role in regulating leptinemia, consistent with previous reports showing that ingestion of HF diets is associated with an increase in leptin levels (Ahren et al. 1997, Stricker-Krongrad et al. 1998, Qi et al. 2008). The changes in the plasma concentrations of both hormones reflect an activation of hunger and a blockade of satiety in order to encourage food intake.

These different hormone profiles influenced the qualitative aspects of feeding behavior differently during the postrestriction period. First, it should be noted that providing access to chow ad libitum to the two groups of rats did not allow them to maintain their weight loss even though the fat content in the chow (5\%) was lower than that in the LF diet. $\mathrm{BW}$ rebound was complete after 3 weeks. In the first $24 \mathrm{~h}$ of refeeding, there was no difference in chow intake between HEPa and LF rats. Both groups ingested a large meal during the very first hour of refeeding. Therefore, drive to feed was activated because the quantity of food ingested during this time corresponded to what is generally taken in by overnight food-deprived rats (Beck et al. 2005). This drive did not decrease after $24 \mathrm{~h}$, as shown by the fact that when an HEPa diet was provided during the 25th hour as a test meal, the HEPa rats ingested about the same quantity of energy as during the entire preceding day. The LF rats ate $22 \%$ more calories than during the first hour of their refeeding. 
Thus, neophobia for food does not explain the difference between LF and HEPa rats; satiated LF rats still ingested a supranormal quantity of food in $1 \mathrm{~h}$. The excess of palatable food intake by HEPa rats was rapidly compensated, as, at the end of the first week of refeeding, energy intake between both groups no longer differed.

Binge eating episodes are frequent in animals provided intermittent access to a very low carbohydrate, a high-fat, or a preferred diet (SegalIsaacson et al. 2004, Davis et al. 2007, Cottone et al. 2008). Enthusiasm for the palatable diet but not for the regular chow was noted in both groups, and it persisted throughout the second week. The mechanisms behind this gorging behavior appear to be different for LF than HEPa rats as reflected by differences in the hormone changes. In LF rats, the gorging during the first test meal might be related to the decrease in plasma leptin and the increase in plasma ghrelin. In HEPa rats, gorging was related to the only increase in ghrelin; however, there could also have been a learning component involved as these rats had already been exposed to this diet. Thus, previous dietary experience appeared to have a much stronger influence on feeding behavior than down-regulation of leptin as demonstrated by the differences in HEPa diet intake between the groups during the first test meal. This interpretation was confirmed by the hormone levels measured after 1 week of refeeding. HEPa rats continued to have high ghrelin levels, which stimulated their food intake and induced their second gorging episode consistent with a role for ghrelin in the brain reward pathways (Naleid et al. 2005). LF rats continued to have lower leptin levels, whereas their ghrelin levels returned to normal. The second gorging episode in the LF rats should have been less substantial than the first one because their ghrelin levels had returned to baseline. However, they had an initial positive experience with the palatable diet during the first test meal, which reinforced their interest for the high-fat diet during the second test meal. This supports the importance of associative learning in feeding behavior. A recent report has also substantiated the influence of leptin on gorging behavior. As with the LF rats in our experiment, selected mice showing gorging episodes are characterized by a hormone profile including lower leptin levels associated with unmodified ghrelin levels (Hambly et al. 2007). Our data confirm that in obese Zucker rats, the brain reward system is sensitive to leptin despite the deficiency of fully operational leptin receptors (Fulton et al. 2004).

We cannot discount a possible influence on gorging behavior by other parameters sensitive to weight loss, such as hypothalamic neuropeptides that are dependent on the nutritional state and diet composition, that interact with leptin or are engaged in reward like neuropeptide Y (Brown et al. 2000, Beck 2006). Further studies will show whether qualitatively modulated restriction affects the brain profiles of these peptides.

Increasing the number of such gorging episodes would accelerate weight gain and restore initial fat stores. Thus, it appears that the period directly following the restriction period is critical for BW regulation since gorging was only noted when highly palatable food was available and not with chow. The HEPa diet has some characteristics (energy density and high fat content) similar to those of craved foods (Gilhooly et al. 2007). Thus, greater vigilance in terms of dietary patterns and a combined therapy with drugs that could limit the ghrelin surge and enhance leptin secretion might help obese people to maintain their weight, leading to a healthier life. Drugs that modulate the ingestion of palatable food such as cannabinoid antagonists might also be useful.

Our study needs to be extended in the diet-induced obese rat, which better reflects common human obesity and in different rat strains, since genetic background is an important parameter controlling an animal's adaptation strategy in response to food restriction (Evans et al. 2005, Gelegen et al. 2006).

\section{Declaration of interest}

The authors have no conflict of interest to declare.

\section{Funding}

This research did not receive any specific grant from any funding agency in the public, commercial, or not-for-profit sector.

\section{References}

Ahren B, Mansson S, Gingerich RL \& Havel PJ 1997 Regulation of plasma leptin in mice: influence of age, high-fat diet, and fasting. American Journal of Physiology 42 R113-R120.

AlBarazanji KA, Buckingham RE, Arch JRS, Haynes A, Mossakowska DE, McBay DL, Holmes SD, McHale MT, Wang XM \& Gloger IS 1997 Effects of intracerebroventricular infusion of leptin in obese Zucker rats. Obesity Research 5 387-394.

Barazzoni R, Zanetti M, Stebel M, Biolo G, Cattin L \& Guarnieri G 2003 Hyperleptinemia prevents increased plasma ghrelin concentration during short-term moderate caloric restriction in rats. Gastroenterology 124 1188-1192.

Beck B 2006 Neuropeptide Y in normal eating and in genetic and dietaryinduced obesity. Philosophical Transactions of the Royal Society of London. Series B: Biological Sciences 361 1159-1185.

Beck B \& Richy S 2008 Differential long-term dietary regulation of adipokines, ghrelin, or corticosterone: impact on adiposity. Journal of Endocrinology 196 171-179.

Beck B, Musse N \& StrickerKrongrad A 2002 Ghrelin, macronutrient intake and dietary preferences in Long-Evans rats. Biochemical and Biophysical Research Communications 292 1031-1035.

Beck B, Richy S \& StrickerKrongrad A 2003 Ghrelin and body weight regulation in the obese Zucker rat in relation to feeding state and dark/light cycle. Experimental Biology and Medicine 228 1124-1131.

Beck B, Max JP, Fernette B \& Richy S 2004 Adaptation of ghrelin levels to limit body weight gain in the obese Zucker rat. Biochemical and Biophysical Research Communications 318 846-851.

Beck B, Fernette B \& StrickerKrongrad A 2005 Peptide S is a novel potent inhibitor of voluntary and fast-induced food intake in rats. Biochemical and Biophysical Research Communications 332 859-865.

Bray GA 1977 The Zucker-fatty rat: a review. Federation Proceedings 36 146-153. 
Brown CM, Coscina DV \& Fletcher PJ 2000 The rewarding properties of neuropeptide $\mathrm{Y}$ in perifornical hypothalamus vs nucleus accumbens. Peptides 21 1279-1287.

Chua SC, White DW, Wupeng XS, Liu SM, Okada N, Kershaw EE, Chung WK, Powerkehoe L, Chua M, Tartaglia LA et al. 1996 Phenotype of fatty due to Gln269Pro mutation in the leptin receptor (lepr). Diabetes 45 1141-1143.

Considine RV, Sinha MK, Heiman ML, Kriauciunas A, Stephens TW, Nyce MR, Ohannesian JP, Marco CC, Mckee LJ, Bauer TL et al. 1996 Serum immunoreactive leptin concentrations in normal-weight and obese humans. New England Journal of Medicine 334 292-295.

Cottone P, Sabino V, Steardo L \& Zorrilla EP 2008 Opioid-dependent anticipatory negative contrast and binge-like eating in rats with limited access to highly preferred food. Neuropsychopharmacology 33 524-535.

Cummings DE, Purnell JQ, Frayo RS, Schmidova K, Wisse BE \& Weigle DS 2001 A preprandial rise in plasma ghrelin levels suggests a role in meal initiation in humans. Diabetes 50 1714-1719.

Cummings DE, Weigle DS, Frayo RS, Breen PA, Ma MK, Dellinger EP \& Purnell JQ 2002 Plasma ghrelin levels after diet-induced weight loss or gastric bypass surgery. New England Journal of Medicine 346 1623-1630.

Dansinger ML, Gleason JA, Griffith JL, Selker HP \& Schaefer EJ 2005 Comparison of the Atkins, Ornish, Weight watchers, and Zone diets for weight loss and heart disease risk reduction. Journal of the American Medical Association 293 43-53.

Davis JF, Melhorn SJ, Shurdak JD, Heiman JU, Tschop MH, Clegg DJ \& Benoit SC 2007 Comparison of hydrogenated vegetable shortening and nutritionally complete high-fat diet on limited access-binge behavior in rats. Physiology \& Behavior 92 924-930.

Evans SA, Messina MM, Knight WD, Parsons AD \& Overton JM 2005 Long-Evans and Sprague-Dawley rats exhibit divergent responses to refeeding after caloric restriction. American Journal of Physiology. Regulatory, Integrative and Comparative Physiology 288 R1468-R1476.

Fulton S, Richard D, Woodside B \& Shizgal P 2004 Food restriction and leptin impact brain reward circuitry in lean and obese Zucker rats. Behavioural Brain Research 155 319-329.

Gelegen C, Collier DA, Campbell IC, Oppelaar H \& Kas MJH 2006 Behavioral, physiological, and molecular differences in response to dietary restriction in three inbred mouse strains. American Journal of Physiology. Endocrinology and Metabolism 291 E574-E581.

Gilhooly CH, Das SK, Golden JK, McCrory MA, Dallal GE, Saltzman E, Kramer FM \& Roberts SB 2007 Food cravings and energy regulation: the characteristics of craved foods and their relationship with eating behaviors and weight change during 6 months of dietary energy restriction. International Journal of Obesity 31 1849-1858.

Golay A, Allaz AF, Morel Y, Detonnac N, Tankova S \& Reaven G 1996 Similar weight loss with low- or high-carbohydrate diets. American Journal of Clinical Nutrition 63 174-178.

Gomez G, Englander EW \& Greeley GH 2004 Nutrient inhibition of ghrelin secretion in the fasted rat. Regulatory Peptides 117 33-36.

Hambly C, Simpson CA, McIntosh S, Duncan JS, Dalgleish GD \& Speakman JR 2007 Calorie-restricted mice that gorge show less ability to compensate for reduced energy intake. Physiology \& Behavior 92 985-992.

Hansen TK, Dall R, Hosoda H, Kojima M, Kangawa K, Christiansen JS \& Jorgensen JOL 2002 Weight loss increases circulating levels of ghrelin in human obesity. Clinical Endocrinology 56 203-206.

Iida M, Murakami T, Ishida K, Mizuno A, Kuwajima M \& Shima K 1996 Substitution at codon 269 (glutamine $\rightarrow$ proline) of the leptin receptor (OB-r) cDNA is the only mutation found in the Zucker fatty $(\mathrm{fa} / \mathrm{fa})$ rat. Biochemical and Biophysical Research Communications 224 597-604

Kalra SP, Bagnasco M, Otukonyong EE, Dube MG \& Kalra PS 2003 Rhythmic, reciprocal ghrelin and leptin signaling: new insight in the development of obesity. Regulatory Peptides 111 1-11.

LaraCastro C \& Garvey WT 2004 Diet, insulin resistance, and obesity: zoning in on data for Atkins dieters living in South Beach. Journal of Clinical Endocrinology and Metabolism 89 4197-4205.
Lee HM, Wang GY, Englander EW, Kojima M \& Greeley GH 2002 Ghrelin, a new gastrointestinal endocrine peptide that stimulates insulin secretion: enteric distribution, ontogeny, influence of endocrine, and dietary manipulations. Endocrinology 143 185-190.

Leidy HJ, Dougherty KA, Frye BR, Duke KM \& Williams NI 2007 Twentyfour-hour ghrelin is elevated after calorie restriction and exercise training in non-obese women. Obesity 15 446-455.

vanderLely AJ, Tschop M, Heiman ML \& Ghigo E 2004 Biological, physiological, pathophysiological, and pharmacological aspects of ghrelin. Endocrine Reviews 25 426-457.

Moesgaard SG, Ahren B, Carr RD, Gram DX, Brand CL \& Sundler F 2004 Effects of high-fat feeding and fasting on ghrelin expression in the mouse stomach. Regulatory Peptides 120 261-267.

Morpurgo PS, Resnik M, Agosti F, Cappiello V, Sartorio A \& Spada A 2003 Ghrelin secretion in severely obese subjects before and after a 3-week integrated body mass reduction program. Journal of Endocrinological Investigation 26 723-727.

Naleid AM, Grace MK, Cummings DE \& Levine AS 2005 Ghrelin induces feeding in the mesolimbic reward pathway between the ventral tegmental area and the nucleus accumbens. Peptides 26 2274-2279.

Qi X, Reed JT, Wang GY, Han S, Englander EW \& Greeley GH 2008 Ghrelin secretion is not reduced by increased fat mass during diet-induced obesity. American Journal of Physiology. Regulatory, Integrative and Comparative Physiology 295 R 429-R 435.

Reinehr T, Roth CL, Alexy U, Kersting M, Kiess W \& Andler W 2005 Ghrelin levels before and after reduction of overweight due to a low-fat high-carbohydrate diet in obese children and adolescents. International Journal of Obesity 29 362-368.

Sanchez J, Oliver P, Palou A \& Pico C 2004 The inhibition of gastric ghrelin production by food intake in rats is dependent on the type of macronutrient. Endocrinology 145 5049-5055.

SegalIsaacson CJ, Johnson S, Tomuta V, Cowell B \& Stein DT 2004 A randomized trial comparing low-fat and low-carbohydrate diets matched for energy and protein. Obesity Research 12 130S-140S.

Sinha MK, Ohannesian JP, Heiman ML, Kriauciunas A, Stephens TW, Magosin S, Marco C \& Caro JF 1996 Nocturnal rise of leptin in lean, obese, and non-insulin-dependent diabetes mellitus subjects. Journal of Clinical Investigation 97 1344-1347.

Stricker-Krongrad A, Cumin F, Burlet C \& Beck B 1998 Hypothalamic neuropeptide $\mathrm{Y}$ and plasma leptin after long-term high-fat feeding in the rat. Neuroscience Letters 254 157-160.

Tschop M, Smiley DL \& Heiman ML 2000 Ghrelin induces adiposity in rodents. Nature $\mathbf{4 0 7}$ 908-913.

Tschop M, Weyer C, Tataranni PA, Devanarayan V, Ravussin E \& Heiman ML 2001 Circulating ghrelin levels are decreased in human obesity. Diabetes 50 707-709.

Wang TL, Hartzell DL, Flatt WP, Martin RJ \& Baile CA 1998 Responses of lean and obese Zucker rats to centrally administered leptin. Physiology and Behavior 65 333-341.

Williams DL, Grill HJ, Cummings DE \& Kaplan JM 2006 Overfeedinginduced weight gain suppresses plasma ghrelin levels in rats. Journal of Endocrinological Investigation 29 863-868.

Yancy WS, Olsen MK, Guyton JR, Bakst RP \& Westman EC 2004 A low-carbohydrate, ketogenic diet versus a low-fat diet to treat obesity and hyperlipidemia - a randomized, controlled trial. Annals of Internal Medicine 140 769-777.

Received in final form 1 April 2009

Accepted 20 April 2009

Made available online as an Accepted Preprint 20 April 2009 